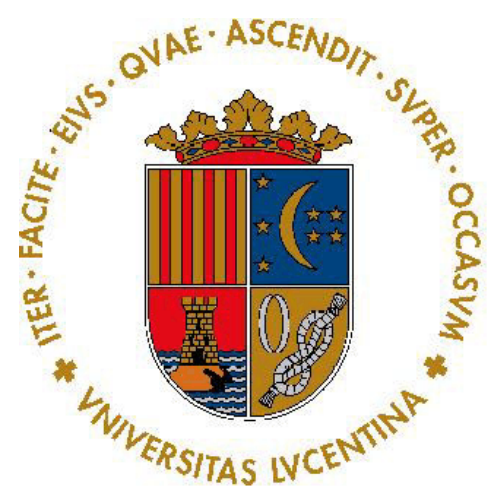

Facultad de Ciencias Económicas y Empresariales

Memoria del Trabajo de Fin de Máster

El Sistema de Gestión Integrado de Destino y su papel en el actual escenario turístico. Un análisis aplicado a la Red de Destinos Turísticos Inteligentes de la Comunitat Valenciana.

\author{
Marc Fuster Uguet \\ Máster Universitario en Dirección y Planificación del \\ Turismo
}

Año académico 2019-20

DNI del alumno: 41541644X

Trabajo tutelado por: Dr. David Giner Sánchez.

Departamento de Análisis Geográfico Regional y Geografía Física

Se autoriza a la Universidad a incluir este trabajo en el Repositorio Institucional para su consulta en acceso abierto y difusión en línea, con fines exclusivamente académicos y de investigación. 
A mi familia, amistades y al fútbol de los domingos. 


\section{Índice de contenidos}

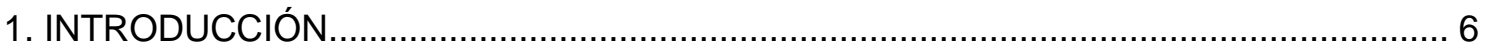

2. RETOS Y RESPONSABILIDADES DEL MODELO DE GESTIÓN DE DESTINO ANTE

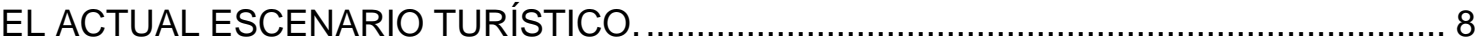

3. EL SISTEMA DE GESTIÓN INTEGRADO DE DESTINO. FUNCIONES, ESCALAS TERRITORIALES Y RETOS.

3.1. Componentes, estructura y funcionalidades del Sistema de Gestión Integrado de

3.2. Las escalas territoriales del Sistema de Gestión Integrado de Destino. 23

3.3. Implicaciones y retos del Sistema de Gestión Integrado del Destino 24

4. METODOLOGIA Y FUENTES DE INFORMACIÓN. 27

5. RESULTADOS DE LA INVESTIGACIÓN. 30

5.1. Tratamiento y análisis de los datos durante el proceso de gestión del destino. ...... 30

5.2. Relevancia y retos del SGID para gestión del destino. 35

5.3. Grado de desarrollo y formación TIC de las organizaciones de gestión turística. ... 39

6. CONCLUSIONES Y RECOMENDACIONES 42

7. BIBLOGRAFIA. 46 


\section{Índice de Figuras y Tablas}

Figura 1. Implicaciones y retos de las organizaciones de gestión del destino...............8

Figura 2. Modelo de gestión de la OGD...............................................................

Figura 3. Dimensiones de la gestión turística de un destino...................................14

Figura 4. Modelo de un Sistema de Gestión Integrado de Destino..............................18

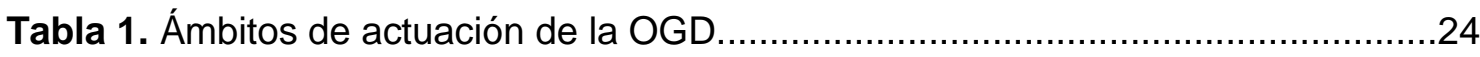

Tabla 2. Cuadro-resumen de las principales implicaciones y retos de los SGID.........25

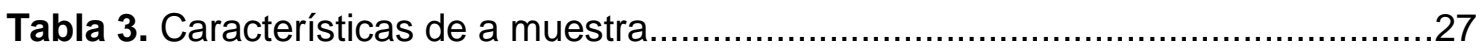

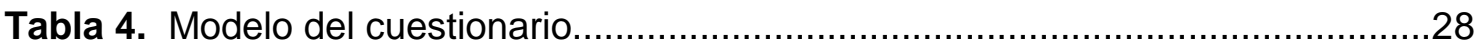

Tabla 5. Valoración de la importancia de los datos en la gestión de los destinos

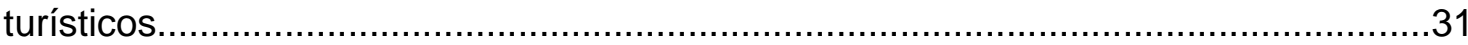

Figura 5. Valoración de la importancia de los datos en la gestión de los destinos turísticos, según la fuente de información.................................................................

Tabla 6. Valoración de la relevancia de los datos en la gestión de los destinos turísticos, según la fuente.

Tabla 7. Valoración de la utilidad de los datos en la gestión de los destinos turísticos.

Tabla 8. Cuadro-resumen de las principales oportunidades y dificultades de un SGID

Tabla 9. Cuadro-resumen de las principales líneas de acción para fomentar la implementación de un SGID. 


\title{
EL SISTEMA DE GESTIÓN INTEGRADO DE DESTINO Y SU PAPEL EN EL ACTUAL ESCENARIO TURÍSTICO. UN ANÁLISIS APLICADO A LA RED DE DESTINOS TURÍSTICOS INTELIGENTES DE LA COMUNITAT \\ VALENCIANA.
}

\begin{abstract}
:
El presente trabajo analiza los sistemas de gestión integrado de destino ante el actual escenario turístico. Se estudia acerca de sus funcionalidades e implicaciones y se realiza una propuesta de conceptualización desde una perspectiva sistémica que se constata mediante una encuesta a los destinos adheridos a la Red DTI-CV. Los resultados ponen de manifiesto la necesidad de contar con este tipo de herramienta para una mejora en el proceso de gobernanza turística. Sin embargo, su implementación tiene numerosos impedimentos que imposibilitan, por el momento, su pleno desarrollo. Por este motivo, se sintetizan cuatro recomendaciones generales y sus principales líneas de acción, para así fomentar el desarrollo del sistema de gestión integrado de destino.
\end{abstract}

Palabras clave: Sistema de Gestión Integral de Destino, Tecnologías de la Información y Comunicación, Destinos inteligentes, Gobernanza turística, Innovación, Datos. 


\section{INTRODUCCIÓN.}

Tal y como señalan Benckendorff, Sheldon y Fesenmaier (2014) el actual ecosistema turístico se caracteriza por un uso intensivo de información, que debe ser procesado y analizado para la gestión turística del destino.

Por ello, las organizaciones de gestión de destino (OGD, en adelante), están introduciendo, de manera paulatina, cambios cualitativos en los procedimientos de gestión de la información turística.

Estos cambios hacen referencia a la adopción de las tecnologías de la información y comunicación (TIC, en adelante) en las estructuras y actuaciones de los entes gestores que permiten el liderazgo estratégico y operativo.

En este sentido, ha adquirido relevante peso la planificación turística inteligente (Ivars-Baidal y Vera, 2019) por su capacidad para integrar las TIC en los procesos de gobernanza del destino.

De acuerdo con Ivars, Solsona y Giner (2016) el interés por la planificación y gestión inteligente del destino coincide con la aparición de nuevos desafíos y cambios en el mercado turístico que someten a las OGD al requisito apremiante de desarrollar nuevos enfoques de gestión de la información.

Según Giner (2017), todas las estrategias de gestión que lleva a cabo un OGD generan y requieren la recopilación, la sistematización y el procesamiento de datos para su transformación en información útil y precisa para la consecución de una toma de decisión.

Por este motivo, el sistema de gestión integrado de destino (SGID, en adelante) constituye una herramienta clave sobre las que pivotan las responsabilidades de las organizaciones de gestión de destino, tanto desde el punto de vista estratégico como operativo, y cuya función principal es la coordinación de los flujos y registros de los datos generados dentro del sistema turístico.

En este contexto, el presente trabajo tiene por objetivo analizar en qué medida el SGID pueden ser capaces de dar respuesta a las nuevas implicaciones de las OGD ante el actual escenario turístico. En primer lugar, se contextualizan los retos y las responsabilidades de las organizaciones de gestión de destino 
ante los desafíos actuales. En segundo lugar, se definen las características, funcionalidades e implicaciones del sistema de gestión de destino. En tercer lugar, se muestran los resultados de la investigación en relación a los beneficios e impedimentos del uso del SGID en los destinos adheridos a la RED-DTI Comunitat Valenciana. Finalmente, se exponen una serie de conclusiones relacionadas con la línea teórica y los resultados de la investigación, así como se plantean recomendaciones para fomentar el desarrollo de un SGID en un destino. 


\section{RETOS Y RESPONSABILIDADES DEL MODELO DE GESTIÓN DE DESTINO ANTE EL ACTUAL ESCENARIO TURÍSTICO.}

$\mathrm{Si}$ bien es cierto que el visitante sigue siendo el elemento principal para comprender y analizar el turismo, resulta fundamental el análisis del modelo de gestión de los destinos para afrontar los nuevos retos e implicaciones del sector turístico (Pike, 2008). Sin embargo, las estrategias de gestión de los destinos son complejas y necesitan un enfoque holístico y sistemático para su comprensión.

En una tendencia de crecimiento continuo y de extensión al conjunto de regiones y países, la actividad turística ha requerido iniciativas de gestión efectivas $\mathrm{e}$ integradas que han supuesto cambios estratégicos en las estructuras y en los cometidos de las organizaciones competentes de la gestión del destino.

Para tratar de entender los cambios estratégicos que deberían experimentar las OGD, es importante conceptualizar las implicaciones y retos que caracterizan el actual ecosistema turístico (Figura 1).

Figura 1. Implicaciones y retos de las organizaciones de gestión del destino.

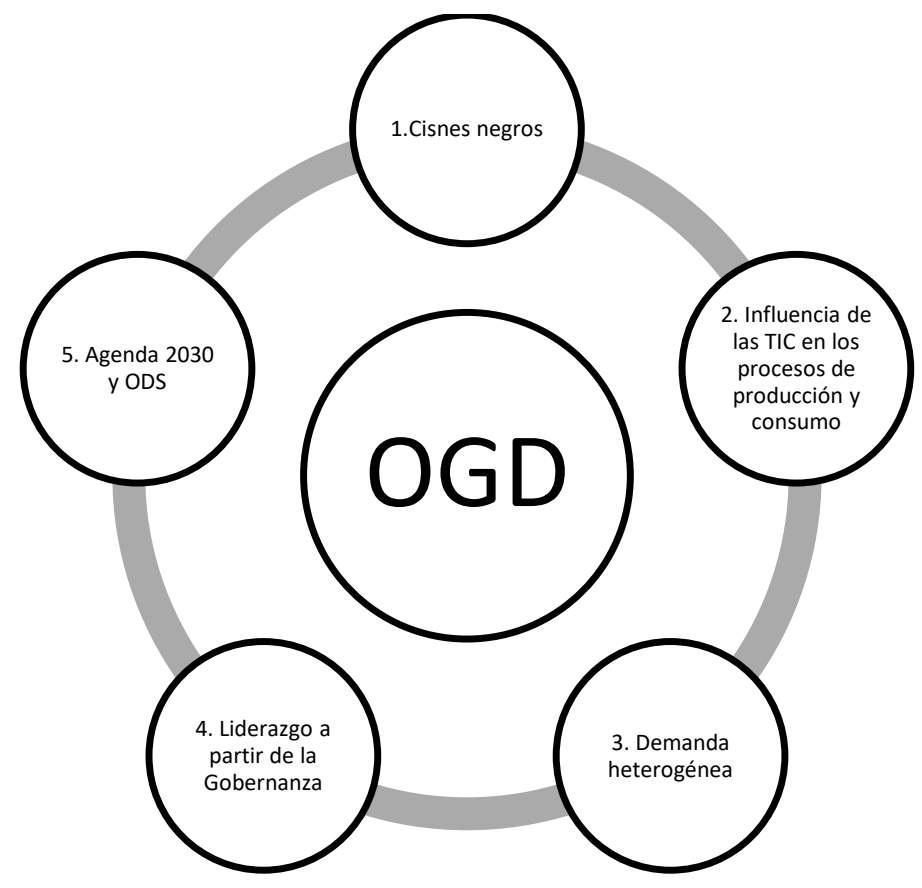

Elaboración propia 
En primer lugar, algunos acontecimientos de repercusión global están mermando el clima de confianza y las expectativas del mercado turístico. En el ámbito económico, estos sucesos son descritos utilizando la teoría del cisne negro, metáfora que hace referencia a aquellos acontecimientos que ocurren por sorpresa, porque, a priori, son improbables y que, para bien 0 , generalmente, para mal, terminan teniendo un gran impacto y repercusiones trascendentales. Es por eso, que para paliar los efectos de los cisnes negros es necesaria una planificación flexible y dinámica capaz de desarrollar iniciativas de contingencia ante episodios terroristas como los sucedidos en Niza; ante pandemias mundiales como la del COVID19; $u$ ante otros episodios con un enorme impacto turístico.

En este sentido, las OGD tienen que desarrollar estrategias e iniciativas en torno a diferentes escenarios económicos y proveerse de planes de contingencia para mitigar acontecimientos singulares, totalmente inesperados y con un enorme impacto global, para así aumentar la capacidad de resiliencia del destino (Wang y Pizam, 2011; Scarpino y Gretzel, 2015).

Por ejemplo, la Agencia Estratégica Turística de las Islas Baleares ha realizado un informe de escucha online del impacto del COVID19 en el sector turístico del destino por mercados emisores. La intención es elaborar un plan directriz para el reposicionamiento de marca y mejora de la reputación online ante la crisis sanitaria.

En segundo lugar, las tecnologías de la información y la comunicación están teniendo un enorme impacto en los procesos de producción y de consumo turístico. Por un lado, la integración de las TIC en los procesos estratégicos y operativos de los destinos ha posibilitado el surgimiento de un nuevo modelo gestión conocido como Smart Destination (Ivars-Baidal, et al., 2017). Por otro lado, los propios visitantes también han experimentado cambios a raíz de la socialización de las TIC.

De acuerdo con Femenia-Serra, Neuhofer e Ivars-Baidal (2018), los visitantes se están adaptando al nuevo ecosistema digital, dando lugar a nuevas actitudes y cambios en los procesos de interrelación con el destino. 
Frente a eso se hace imprescindible contar con un mandato estratégico, de coordinación y gestión en el marco de una estructura de gobernanza adecuada a los distintos desafíos y cambios de paradigma surgidos, a raíz del nuevo ecosistema digital (Giner, 2017).

En tercer lugar, la demanda ha experimentado un proceso de heterogeneización. Varios autores como Cohen (2005) y Vera et al (2011) señalan que las nueva formas de consumo responden a múltiples necesidades y preferencias propias de las actitudes y comportamientos de la Sociedad postindustrial (Bell, 1973) que se encaminan hacia la participación activa en las experiencias turísticas.

Por este motivo, las OGD deben permanentemente innovar y rediseñar sus estrategias de producto (inteligencia de mercado), los servicios turísticos y la imagen proyectada para ser capaces de satisfacer una demanda cada vez más segmentada para así mantener su competitividad en el mercado (Díaz y Santana, 2016).

En cuarto lugar, la gobernanza se ha convertido en uno de los elementos clave en el ámbito de la gestión turística (Song et al., 2013). De acuerdo con PulidoFernández y Pulido-Fernández (2014:687), las OGD deben de tener como objetivo "dirigir efectivamente el turismo en los diferentes niveles de gobierno, a través de las formas de coordinación, colaboración y/o cooperación (...) eficaces y transparentes" De este forma, se ayudará a alcanzar los objetivos comunes para el ecosistema turístico, facilitando el consenso y el aprendizaje durante la gestión del destino (Pulido-Fernández y Pulido-Fernández, 2014).

Y por el último, en quinto lugar, la OMT (2019) aboga a que el modelo de gestión del destino debe adecuarse a la Agenda 2030 para el Desarrollo Sostenible y a los Objetivos de Desarrollo Sostenible (en adelante, ODS) lo que permitirá al ecosistema turístico, en general, y a los destinos en particular, un desarrollo sostenible y competitivo a medio y largo plazo.

Por tanto, ante el actual escenario turístico (Figura 1) es importante entender la necesidad de desarrollar un modelo de gestión integral que incluya estrategias 
de gestión orientadas a la planificación y desarrollo del producto e iniciativas de mercado (Figura 2).

Sin embargo, hablar del modelo de gestión de las OGD es hacerlo desde un constante debate. La heterogeneidad institucional, regulativa, cultural y territorial de los destinos turísticos pone de manifiesto grandes discrepancias a la hora de enumerar con precisión la misión y la atribución de los gestores turísticos.

El debate sobre qué modelo de gestión deberían de adoptar los entes responsables del destino gira en torno a muchas cuestiones que aún están por resolver.

Algunos autores coinciden que la estrategia de gestión principal de los OGD es la de marketing y promoción (Laesser y Beritelli, 2013; Pike y Page, 2014; Presenza, Sheehan y Ritchie, 2005). Giner (2016) citando a Pike y Pige (2014) afirma que esa tendencia se debe a la caracterización ubicua de las estrategias de marketing y promoción, impulsadas por la influencia de las TIC en los procesos de producción y consumo turístico. De ahí, a que varios autores se posicionen a favor del término Organización de Marketing de Destino (OMD) en detenimiento del de Organización de Gestión de Destino, dada la heterogeneidad institucional y regulativa de las implicaciones de la planificación y gestión de los destinos.

No obstante, Bornhorst, Brent-Ritchie y Sheehan (2010) reconocen la existencia de una línea creciente de expertos que afirman que frente a los distintos retos y desafíos turísticos actuales, son muchas las OMD que han evolucionado hacia la inclusión estrategias de gestión integral para garantizar la competitividad y la sostenibilidad del destino (ECM, 2017; OMT, 2019).

Paradigmáticos son los ejemplos de Barcelona y Tenerife. Ambas OMD han sido pioneras a la hora de incluir funciones de planificación y desarrollo a los tradicionales cometidos de promoción turística, evolucionando hacia un modelo de gestión integral. 
De acuerdo con la Figura 2 en un modelo de gestión integral, las OGD deben establecer sus estrategias de gestión basándose en un cuadro de responsabilidades bifuncional.

Figura 2. Modelo de gestión de la OGD.

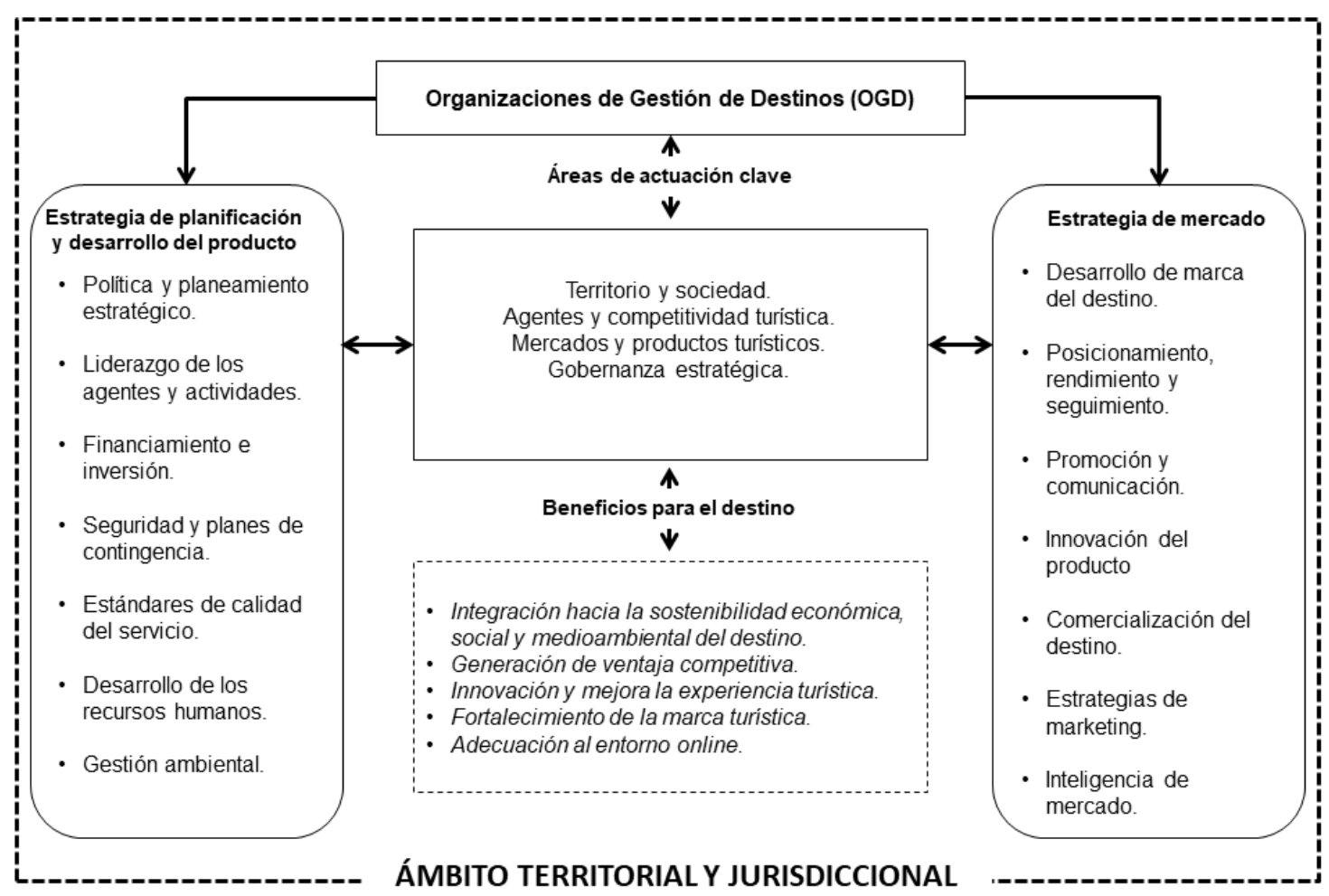

Elaboración propia a partir de Pearce (2016) y Wang (2011)

Por una parte, se deben desarrollar responsabilidades en favor de la planificación, desarrollo y liderazgo del destino; y por otra, orientar estrategias de gestión al mercado, es decir, al marketing y a la promoción. En este sentido, es importante que los gestores del destino centren sus esfuerzos en la gestión de ambas estrategias.

Un enfoque de gestión puramente relacionado con la planificación y desarrollo de destino (creación de producto), corre el riesgo de depender demasiado de la capacidad de sus recursos y productos turísticos, y solamente puede generar ventaja comparativa sobre el resto de los destinos.

En la actual lógica turística, los modelos de gestión basados en la capacidad para generar ventaja comparativa están perdiendo competitividad en el mercado. Por esa razón, en necesario el desarrollo de estrategias sobre el 
mercado (promoción, comercialización, investigación,) con la intención de generar ventaja competitiva (diferenciación) en toda la cadena de valor de la actividad turística.

En este contexto, la convergencia de ambas estrategias (Figura 2) da a lugar a cuatro áreas de actuación claves para el destino, en las que las OGD deben orientar sus iniciativas:

La primera, en el territorio y en la comunidad local, donde se expone la necesaria confluencia de las políticas y planeamiento estratégico (no necesariamente turístico) que intervienen sobre ellas desde una perspectiva turística (recursos humanos, gestión de flujos turísticos, cambio climático y desarrollo sostenible, seguridad y planes de contingencia, etc.).

La segunda, en relación a los agentes y a la competitividad turística cuyo ámbito se le atribuyen iniciativas que se interrelacionan con la necesidad de dar mayor soporte a la competitividad (mediante la comercialización del destino, influencia de las TIC, gestión de la calidad turística, etc.).

La tercera, en los mercados y productos turísticos donde se incide en la estructuración de los productos turísticos según la actual forma de consumir, por lo que tan importante resulta la planificación y desarrollo del recurso turístico (ventaja comparativa) como la generación de ventaja competitiva a partir de diseño de estrategias del mercado.

Finalmente, y como base de las tres anteriores, es fundamental gestionar el ámbito de la gobernanza turística como el eje principal que permite que todos los engranajes del destino turístico funcionen debidamente. En este sentido, se incluye; el liderazgo estratégico de la agentes y actividades turísticas; la cooperación y coordinación interinstitucional; el modelo económico; y la regulación y ejecución eficaz. 


\section{EL SISTEMA DE GESTIÓN INTEGRADO DE DESTINO. FUNCIONES, ESCALAS TERRITORIALES Y RETOS.}

En el epígrafe anterior se han señalado cinco responsabilidades a los que una OGD debería orientar su gestión para acometer de forma eficaz y racional los retos derivados del nuevo ecosistema turístico.

La gestión turística que integra la organización, dirección y coordinación de todas las acciones, estratégicas y operativas, de los medios y recursos disponibles es la encargada de garantizar la aplicación de los instrumentos de planificación turística que determinarán los objetivos del desarrollo turístico del destino y los medios para alcanzarlos (Giner, 2016; Vera et al., 2011).

Por este motivo, es importante contar con un modelo que integre los procesos de producción y consumo, abarcando el conjunto de las dimensiones de forman parte del proceso de gestión turística con el fin tomar decisiones eficaces y acertadas (Figura 3).

Figura 3. Dimensiones de la gestión turística de un destino.

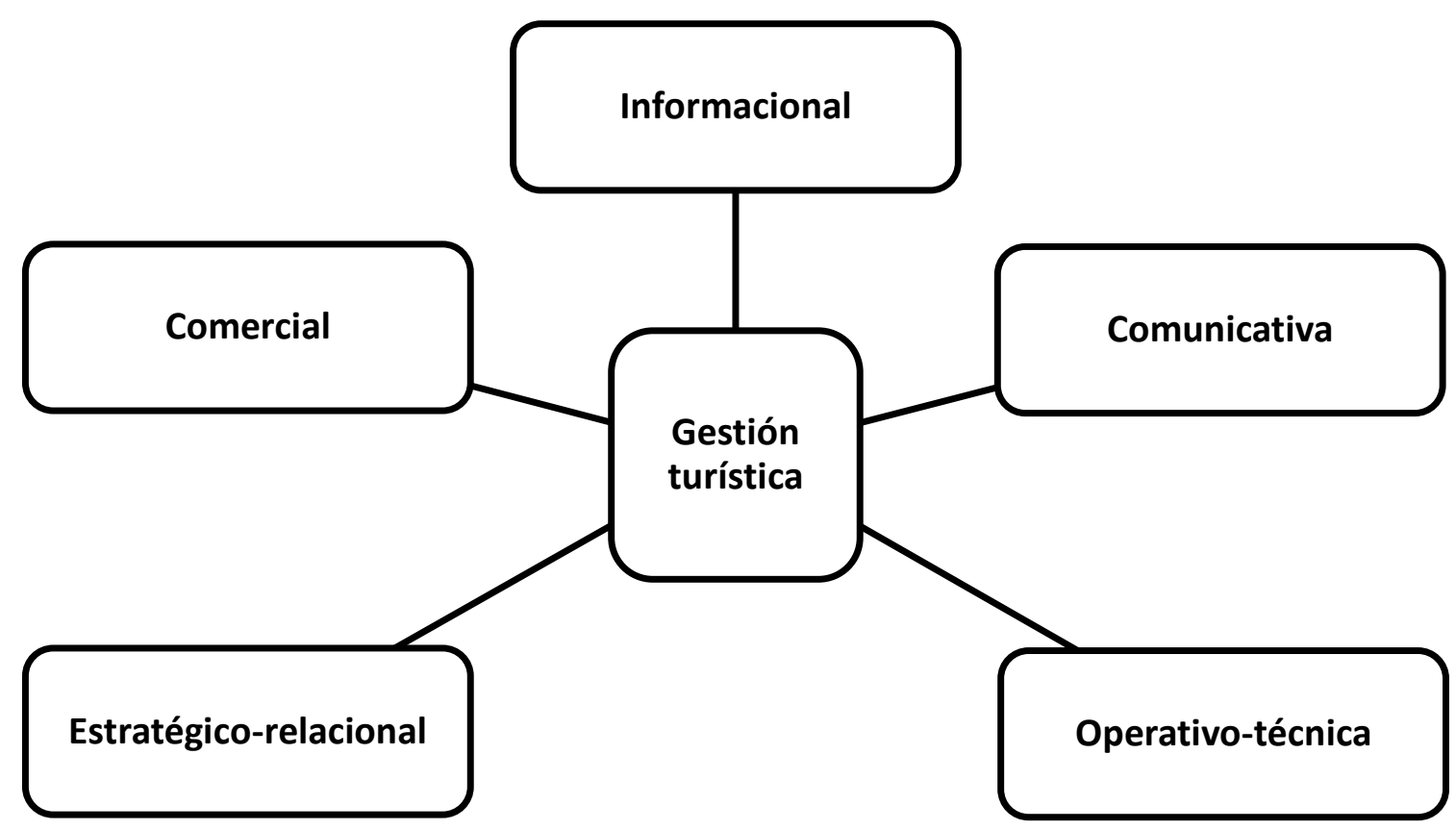

Elaboración propia

Existen cinco dimensiones que tienen que ser consideradas al momento de plantear un modelo de gestión turístico. Estas son: la dimensión informacional, 
la dimensión comunicativa, la dimensión comercial, la estratégico-relacional y, finalmente, la operativo-técnica.

El éxito de un modelo de gestión turístico, reside, en buena parte, de la dimensión informacional. Dicha dimensión comprende el proceso utilizado para la recolección y tratamiento de información útil. Para ello es necesario analizar datos procedentes de todo el ecosistema turístico (visitantes, residentes, empresas, territorio, productos turísticos, etc.) para tomar mejores decisiones estratégicas basada en la información real del destino.

Los controles de calidad de la información son extremadamente importantes (Benckendorff, Sheldon y Fesenmaier, 2014). Si los datos son erróneos o tratados de forma incorrecta, el modelo de gestión turístico pierde eficacia y perspectiva de la realidad turística del destino, y por consiguiente, los gestores de los destino toman decisiones erróneas.

Por ello, cada vez más, destinos, como por ejemplo Benidorm, incorporan herramientas de vigilancia tecnológica e inteligencia competitiva que ayudan a priorizar datos relevantes e información estratégica para su desarrollo competitivo.

La dimensión comunicativa hace referencia a la conexión interactiva entre los actores que intervienen en el sistema turístico de un destino. De este modo, existe por una parte, la comunicación turística (entre la OGD y los actores turísticos, y viceversa) y la promoción del destino en el entorno offline y digital.

La dimensión comercial, muy relacionada con la promoción del destino, incluye el conjunto de acciones para conducir a la demanda al proceso de adquisición de bienes y servicios turísticos que la actividad turística del destino le ofrece. Dicho de otro modo, introduce las estrategias de gestión necesarias para la comercialización del destino.

Aunque tradicionalmente, han sido las empresas e intermediarios turísticos del destino quienes, de forma independiente, han llevado a cabo este proceso de comercializar, autores como Díaz, P. y López, B. (2012) señalan la importancia de contar con técnicas de comercialización bajo una misma marca (motores de 
búsqueda y reserva en el portal web del destino) para la mejora de la rentabilidad y competitividad.

La dimensión estratégico-relacional tiene que ver con todo aquello relacionado con las iniciativas de carácter estratégico y relacional. Es la dimensión en la que tiene lugar la gobernanza del destino.

Y finalmente, la dimensión operativo-técnica hace referencia al conjunto de acciones operativas de la OGD para un modelo de gestión eficaz y eficiente.

Es importante destacar, que la eficacia y eficiencia de un modelo de gestión no reside en el grado de desarrollo de las dimensiones. Hay destinos, que por su idiosincrasia turística y territorial no necesitan una dimensión comunicativa $u$ operativo-técnica muy compleja. Sin embargo, si que resulta imprescindible que cada una de las dimensiones mantengan un intercambio de datos. De lo contrario, se incurre en una situación poco ventajosa a la hora de obtener información estratégica para fomentar la gestión del destino.

Dicho de otro modo, es importante que las dimensiones tengan la capacidad de compartir datos y posibilitar el intercambio de información y conocimiento entre ellas.

La disrupción tecnológica ha proporcionado esta capacidad, dando como resultado la posibilidad de implementar un sistema de gestión integrado de destino.

Un SGID es un modelo de gestión turística basado en las tecnologías de la información y comunicación cuyo propósito es facilitar la recopilación y el procesamiento de los datos mediante la interoperabilidad de los subsistemas que lo conforman. De este modo, resulta más fácil la gestión holística del conjunto de las estrategias y funciones que deben acometer las OGD (Figura 2).

Tal y como señala Giner (2017) todas las dimensiones y procesos de gestión de los destinos (Figura 3) requieren el tratamiento de información útil, precisa y ordenada. Por ello, la recopilación y el procesamiento de los datos resulta clave 
para la planificación de objetivos, ejecución y control de los destinos, tanto desde el punto de vista estratégico como operativo.

En este sentido, de acuerdo con Estevão et al. (2012), y Giner (2016) un SGID permite una serie de ventajas:

Des de un punto de vista estratégico:

- Ofrece soporte a la toma de decisiones para el desarrollo de las estrategias de planificación y de mercado bajo el precepto de la buena gobernanza turística.

- Aumenta la competitividad interna y externa del destino, gracias a la mejora de la coordinación e integración entre los agentes.

- Mejora la experiencia turística durante el ciclo completo de viaje (pre, durante y post), proporcionando, al visitante, información completa y personalizable.

- Fomenta la desintermediación y la interacción directa entre los agentes del ecosistema turístico.

- Actúa como canal de comercialización y distribución para las empresas turísticas del destino para integrarse en la cadena de la oferta turística, organizando y promoviendo experiencias turísticas personalizadas y más variadas.

- Refuerza la promoción y visibilidad y efectividad de la presencia en el mercado.

Y des de un punto de vista operativo:

- Optimiza las relaciones entre los circuitos organizativos de la OGD.

- Introduce innovaciones técnicas y estratégicas acordes con los retos del nuevo ecosistema turístico.

- Aumenta la cantidad o calidad de las acciones estratégicas por recurso empleado. 


\subsection{Componentes, estructura y funcionalidades del Sistema de Gestión Integrado de Destino.}

Existen muchas cuestiones que deberían ser consideradas al momento de diseñar un SGID. No obstante, un SGID tiene que ser entendido como un elemento capaz de integrar todos los procesos de generación y gestión de información de las diferentes dimensiones que conforman el modelo de gestión turístico (Figura 3) para producir servicios, productos y estrategias innovadores para maximizar el valor de cada uno de los agentes turísticos que conforman el ecosistema de un destino.

Tomando como referencia el trabajo de Aguayo (2015), un SGID debería estar diseñado a partir de un núcleo central compuesto de un repositorio de información (base de conocimiento), interconectado con cuatro subsistemas: el subsistema de información, el subsistema de comercialización, el subsistema de dirección y el subsistema de integración.

Figura 4. Modelo de un Sistema de Gestión Integrado de Destino.

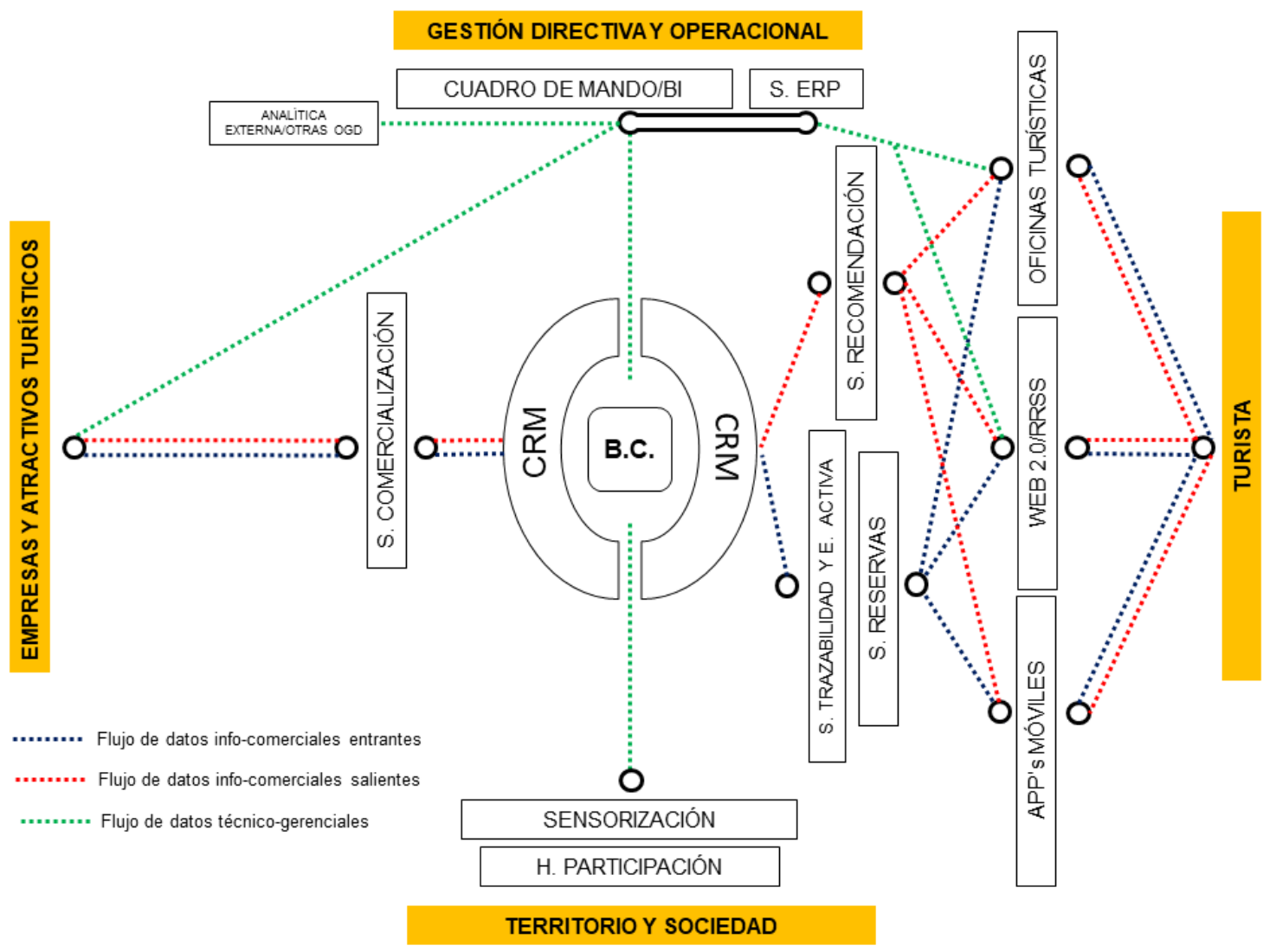

Elaboración propia a partir de Aguayo (2015). 
El subsistema de información es el encargado de albergar la base de conocimiento y de servir de soporte de los demás subsistemas. Tiene como misión el mantenimiento y la gestión eficiente de la información asociada a los atractivos turísticos.

Éste, puede ofrecer dos funciones genéricas: de cara al exterior (front-office) y de cara a la gestión técnico-gerencial del sistema (back-office).

El front-office es la parte del SGID visible para el usuario. Toma la información almacenada en la base de conocimiento y la muestra a través de las tres interfaces de contacto con el visitante.

La primera de ellas hace referencia al portal web y las redes sociales turísticas. Según Zach et al. (2007) ofrecen la posibilidad de llevar a cabo tres funciones: proveer contenido en relación a las atracciones y servicios turísticos; desarrollar técnicas de promoción y marketing (SEO, SEM, Mail Marketing, escucha activa, etc.); y comercializar el destino, mediante la implementación de un módulo de transacción.

La segunda incluye las oficinas turísticas. Éstas constituyen otra interfaz del front-office a través de las cuales los gestores y técnicos del destino interactúan con los visitantes. A raíz de la disrupción de las TIC, los canales tradicionales de contacto con el usuario, han dado paso a los canales digitales, a través del correo electrónico, uso de dispositivos inteligentes, intervención en redes sociales, etc. En este sentido, D'Ambra y Mitilis (2010) y Mastorakis et al. (2015) señalan como la digitalización del sector turístico ha cambiado parte de roles de las oficinas de turismo locales. Por ejemplo, destacan la instauración de los sistemas de recomendación, que permiten ofrecer al usuario una experiencia personalizada y adaptada a sus preferencias a partir de la minería de datos. Además, este sistema puede ser incorporado en los portales web de los destinos o en los dispositivos móviles de los visitantes.

Igualmente, las oficinas de turismo se configuran como un elemento clave para la recogida de información acerca de los visitantes. Éstas son de gran utilidad para suministrar información, por ejemplo, en el sistema de recomendación o en la gestión de la comercialización del destino (sistema de reservas). 
De igual forma, las TIC han permitido la inclusión de nuevas fuentes de datos para la obtención de información sobre el visitante; al tradicional sistema de encuestas se han añadido nuevas herramientas como son los módulos de escucha activa en redes sociales, que tratan, por ejemplo, el análisis de percepción y del sentimiento del turista (Gräbner et al., 2012).

Finalmente, la tercera vía de contacto con el visitante se produce mediante los dispositivos móviles.

De acuerdo con el Instituto de Estadística de las Islas Baleares, más del 70\% de los turistas que visitaron las Islas, durante el 2016, utilizaron, durante su estancia, un dispositivo con acceso a Internet para buscar información sobre el destino. $Y$ es que tal y como apuntan diversos trabajos (Choi, Letho y Oleary, 2007; Ortega, Rodríguez y Kitchen, 2014) el proceso de decisión de compra de los visitantes no termina con la elección del destino, sino que se mantiene durante todo el ciclo del viaje. En consecuencia los SGID tienen que dar respuesta a esta tendencia, desarrollando aplicaciones móvil (apps) o adaptando los portales web a la interfaz móvil.

Igualmente, los dispositivos móviles ofrecen otras funcionalidades vinculadas a su sistema de geoposicionamiento. Entra las cuales destacan los sistemas de trazabilidad, que permiten seguir los flujos de los visitantes en el destino con la finalidad de ofrecer información personalizada (integración con el sistema de recomendación) o para la toma de decisiones estratégicas. Otras de las potencialidades de los dispositivos móviles, son las relacionadas con la realidad aumentada, tratada por autores como Leiva (2014).

El back-office es la parte del SGID que posibilita llevar a cabo todas las operaciones de gestión técnica y gerencial de los diferentes subsistemas.

Por una parte, tiene como objetivo gestionar todo lo relacionado con el diseño, el mantenimiento y la explotación del SGID. Es decir, se encargan de gestionar de manera sostenible la información, de la usabilidad del sistema y sus diferentes subsistemas, de los niveles de seguridad y privacidad, del diseño del portal web, etc. 
Y por la otra, el back-office incluiría el modulo Enterprise Resource Planning (ERP). De acuerdo con Aguayo (2015: 273), "son sistemas de información gerenciales concebidos para dar soporte integral a las OGD en todos los procesos asociados a las operaciones de producción y distribución de sus productos y servicios, así como a todos los procesos relacionados con su organización interna". Así, mediante el uso del sistema ERP se respondería a las propias necesidades de gestión de la información gerencial que, en un sentido integral, tiene el SGID.

El segundo subsistema del cual se basa un SGID, hace referencia a la comercialización del destino, es decir, se encargan de implementar las funcionalidades relacionadas con la reserva y la venta de los atractivos turísticos suministrados por los proveedores del destino.

Este subsistema está integrado por: del sistema central de reservas (propio, ajeno o mixto); del módulo del CRM, que posibilita gestionar de toda la información que se genera en las relaciones que el SGID mantiene con los visitantes (en las oficinas de información, en la escucha activa de redes sociales, en los sistemas de trazabilidad, en el portal web, en las apps, etc.) para realizar marketing relacional (inbound); y de otros elementos que comparte con el subsistema de información, como son el front-office, el sistema de recomendación y, sobre todo, la base de conocimiento.

En relación al CRM, como señala Aguado (2015) puede dar soporte a funcionalidades relacionadas con el soporte a la promoción y la comercialización. Sin embargo, el autor advierte que también puede desempeñar funciones analíticas que se enmarcan dentro del tercer subsistema, el de dirección. Por ejemplo, la aplicación de técnicas de minería de datos para la obtención de información en referencia a las preferencias y a los comportamientos de los turistas, permitiría la re-elaboración de la estrategia de producto del destino.

El tercer subsistema incluye todo lo relacionado con la dirección estratégica y operativa de la OGD. Para afrontar este cometido, es necesario que el SGID disponga de un subsistema que permita: 
Por un lado, que sea capaz de extraer de toda la información estratégica procedente de los subsistemas del SGID y de fuentes externas (otras OGD y analítica externa) para la toma de decisiones a partir del uso de sistemas de apoyo (Business Intelligence, Sistemas de Información Geográfica, etc.).

Y por otro, que gestione toda la información operacional y la procedente del sistema ERT (contabilidad, ventas, nóminas, distribución física de las instalaciones, etc.).

Aunque la mayoría de los módulos (de recomendación, de reserva, ERP, etc.) aportan información sensible al nivel de dirección, destaca especialmente la información del módulo de trazabilidad y del sistema del CRM. Dicha información se cruza con la registrada en la base de conocimiento acerca del comportamiento y las preferencias de los visitantes, mediante técnicas de Business Intelligence (en adelante, BI), dando lugar un conocimiento estratégico para los gestores del destino.

De acuerdo con Aguayo (2015) entre estas destacan: a) generación de informes analíticos; b) cuadros de mando integrales; c) mecanismos de consulta multidimensional; d) herramientas de minería de datos; y d) modelos matemáticos predictivos.

Igualmente, el subsistema de dirección debería de tratar los datos procedentes de la sensorización del destino. Éstos proporcionan apoyo a los servicios técnicos desplegados en el territorio (sensores ambientales, aparcamientos inteligentes, servicios interactivos, etc.).

Otra fuente de información a tener en cuenta es la opinión ciudadana. Por este motivo resulta imprescindible la sensorización continua de la ciudadanía para cometer los procesos de decisión y gestión estratégica.

Y por último, el cuarto subsistema hace referencia a la interconexión e interoperabilidad de todos los subsistemas y módulos que integran el SIGD. EI objetivo es conseguir un modelo de gestión de destino en el que todos los posibles subsistemas y módulos estén integrados entre sí, de forma que puedan cooperar e intercambiar información de una forma eficiente (Aguayo, 2015). 
Para interconectar e interoperar los módulos y subsistemas, Guevara et al. (2010:3) plantea un SGID basado en la tecnología SOA. Esta tecnología "permite la creación e integración de sistemas altamente escalables que se adecuen a la evolución de las estrategias de gestión. Además, esta arquitectura brinda una forma estándar de exposición e invocación de servicios (comúnmente, pero no exclusivamente, servicios web), lo cual facilita la interacción entre diferentes sistemas propios o de terceros y da soporte a las actividades de integración y consolidación".

\subsection{Las escalas territoriales del Sistema de Gestión Integrado de Destino.}

En relación a los ámbitos de actuación de las OGD (Tabla 1), un SGID normalmente es implementado a una escala nacional, regional $\mathrm{y} / \mathrm{o}$ local. No obstante, los SGID regionales y locales son los más comunes.

Tabla 1. Ámbitos de actuación de la OGD.

\begin{tabular}{|c|c|c|}
\hline Ámbito de actuación & Principales funciones & Ejemplo \\
\hline Supranacional & $\begin{array}{lrr}\text {-Desarrollo de } & \text { políticas } & \text { y } \\
\text { recomendaciones en favor } & \text { del } \\
\text { turismo responsable y sostenible } & \end{array}$ & $\begin{array}{c}\text { Organización Mundial } \\
\text { del Turismo }\end{array}$ \\
\hline Nacional & $\begin{array}{l}\text {-Gestión del desarrollo turístico del } \\
\text { país en su conjunto. } \\
\text {-Estrategias orientadas hacia el } \\
\text { marketing y promoción. }\end{array}$ & VisitBritain \\
\hline Regional & $\begin{array}{l}\text {-Planificación y ordenación de la } \\
\text { actividad turística de la región. } \\
\text { - Estrategias orientadas hacia el } \\
\text { marketing y promoción. }\end{array}$ & Visit Central Oregon \\
\hline Orientada al producto turístico & -Gestión orientada al mercado & Visit French Wine \\
\hline Local & $\begin{array}{l}\text {-Gestión integral del destino, tanto en } \\
\text { relación a planificación y desarrollo, } \\
\text { como a las estrategias de mercado. }\end{array}$ & Barcelona Turisme \\
\hline
\end{tabular}

Elaboración propia a partir de Giner (2016).

En países donde la recopilación de datos a nivel nacional puede llegar a ser muy compleja, es preferible el uso de un SGID regional o local. Sin embargo, el diseño de un SGID a nivel nacional, en países pequeños o con un volumen turístico modesto, puede suponer numerosas ventajas para gestionar el destino. Se puede acceder a la información turística de todo el país en una única base de datos; otorga la posibilidad a todas las oficinas de información turística y la red de oficinas turísticas en el extranjero acceder a un SGID centralizado; y facilita la integración con otros módulos de información turística 
como son un CRM o un Sistema de Reservas (Benckendorff, Sheldon y Fesenmaier ,2014). No obstante, las desventajas derivadas de un sistema de gestión centralizado responden a un aumento de los costos de comunicación y a problemas técnicos de diverso índole, como resultado de una arquitectura compleja y extensa.

La alternativa al modelo centralizado pasa por el desarrollo de SGID regionales o locales. Estos diseños son preferibles en países como España o EE.UU. De acuerdo con Benckendorff, Sheldon y Fesenmaier (2014), el diseño de SGID regionales o locales es más adecuado cuando las competencias en el desarrollo y el financiamiento de la actividad turística provienen de un nivel local o regional. Además, disponer de una base de datos regional repercute en un aumento de la veracidad de la información ya que son los gestores turísticos locales los que tienen más conocimiento de la casuística turística de la región.

Igualmente, un sistema de gestión integrado local resulta más apropiado para regiones turísticas heterogenias en cuanto a sus productos turísticos (urbano, sol y playa, activo, de nieve...). Las variables a tener en cuenta para la gestión de un u otro producto pueden llegar a ser completamente diferentes. Así es interesante que para su gestión se disponga de un sistema de gestión independiente para cada uno de los productos turísticos.

\subsection{Implicaciones y retos del Sistema de Gestión Integrado del Destino.}

En el epígrafe anterior se han señalado las bondades de los Sistemas de Gestión del Destino. Sin embargo existen retos e implicaciones a los que un SGID debe hacer frente (Tabla 2):

En primer lugar, autores como Benckendorff, Sheldon y Fesenmaier (2014) y Aguayo (2015) señalan la importancia del conocimiento y la formación en el desarrollo de la tecnología necesaria para la implementación de un SGID. Esta tecnología requiere altos niveles de formación, que en muchos casos, los gestores del destino no tienen. Para ello, antes de realizar ninguna inversión en el sistema, es necesaria la puesta en marcha de iniciativas para el conocimiento y enseñanza de este tipo de herramientas TIC. 
Tabla 2. Cuadro-resumen de las principales implicaciones y retos de los SGID.

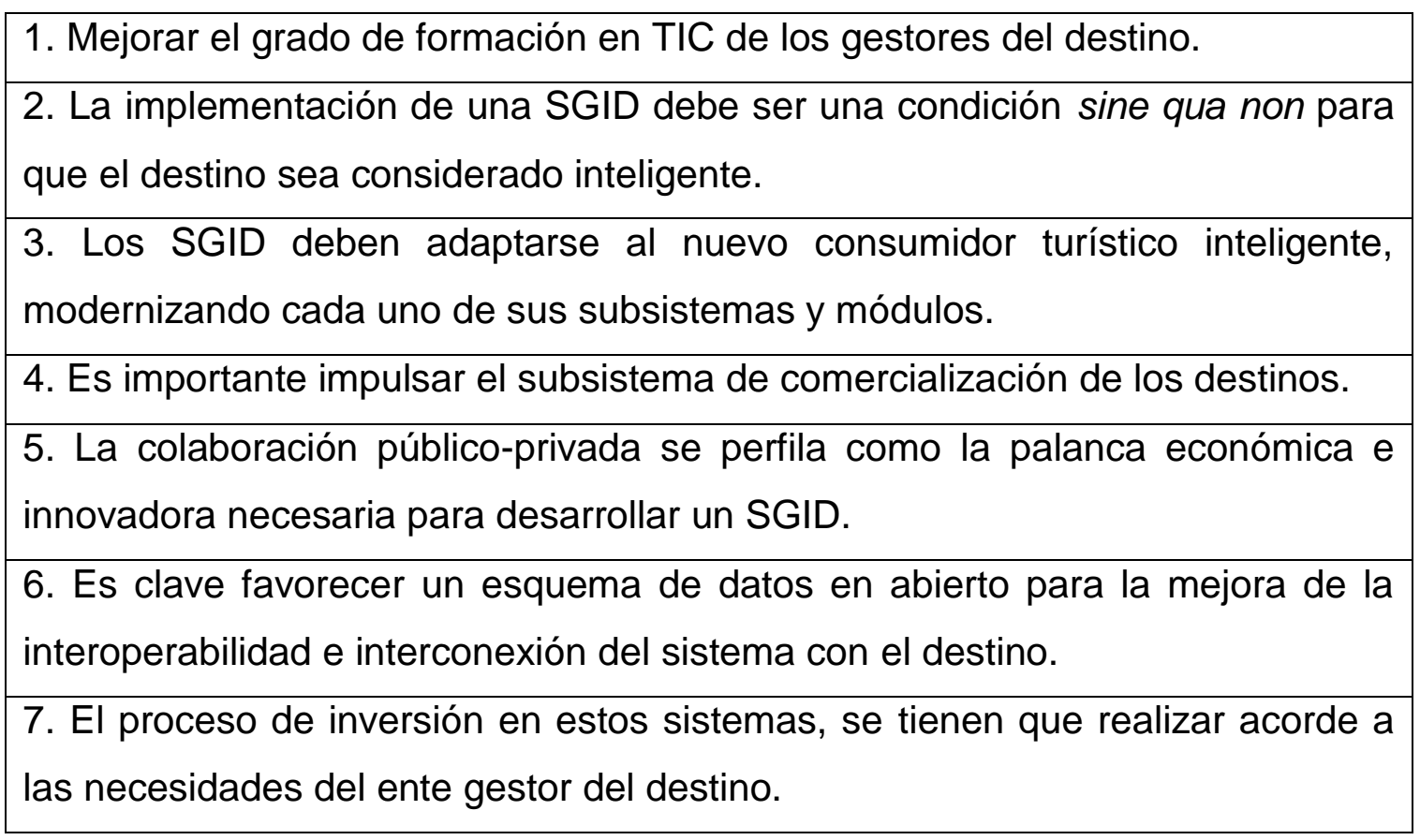

Elaboración propia.

En segundo lugar, el SGID debe ser concebido como el elemento que integre el mundo offline con la esfera digital. Es importante, que el sistema de gestión integrado de destino se plantee como la herramienta principal del modelo de gestión de los destinos Smart. Dicho de otro modo, el SGID debe ser concebido como el sistema nervioso del modelo de gestión inteligente.

En tercer lugar, es importante adaptar el front-office, y en su defecto a todo el SGID al comportamiento del turista inteligente (Femenia-Serra, Neuhofer e Ivars-Baidal, 2018). Es clave la modernización del portal web y de las oficinas de turismo para que se adapten a las nuevas exigencias y preferencias de la digitalización del ecosistema turístico.

En cuarto lugar, es necesario impulsar el uso del subsistema de comercialización del destino. De acuerdo con Guevara (2010), no es fácil encontrar, al menos en España, webs de destinos turísticos que ofrezcan posibilidades de realizar reservas de alojamiento $u$ otros productos turísticos a través de la web oficial del destino.

En quinto lugar, la colaboración público-privada se perfila como la palanca de innovación y de modelo de financiación para incorporar las últimas 
funcionalidades del SGID. Muchas iniciativas en sistemas de gestión de destino, no cristalizan por la falta participación público-privada, imprescindible para el avance y la innovación del destino.

En sexto lugar, es clave favorecer un esquema de datos en abiertos (open data). El uso de datos abiertos favorece la interoperabilidad del sistema y ofrece una mayor eficiencia en los procesos de gestión del destino (CeldránBernabeu, Mazón y Giner, 2018).

Y por último, en séptimo lugar, las OGD deben invertir en la interoperabilidad de los subsistemas que constituyen el sistema de gestión integrado de destino. Tal y como señala Guevara (2010), a veces no es necesario incorporar tecnología punta, basta tomar conciencia de la interoperabilidad de los sistemas existentes, para adaptarlos o cambiarlos. Un correcto diseño, fácilmente usable, e una implantación eficaz permitiría conocer fidedignamente la realidad turística del destino, y orientar la política turística, en consecuencia. 


\section{METODOLOGIA Y FUENTES DE INFORMACIÓN.}

El trabajo se ha fundamentado a partir del análisis de la literatura científica en relación a dos vertientes: por una parte a la conceptualización de los retos y responsabilidades de las organizaciones de gestión del destino ante el actual escenario turístico; y por otra, en qué medida los sistemas de gestión pueden ser capaces de dar respuesta a las nuevas implicaciones de las OGD.

En base a estos dos aspectos, se ha confeccionado el marco teórico, estrechamente condicionado por una producción científica limitada por la novedad de la temática.

Una vez definida la línea teórica del trabajo se ha procedido al análisis de los resultados proporcionados a partir de un cuestionario que fue administrado en el período comprendido entre el mes de abril y diciembre de 2019, mediante un formulario en línea de Google.

El envío y recepción del cuestionario se coordinó desde el Instituto Valenciano de Tecnologías Turísticas (INVAT.TUR) obteniendo un total de 25 respuestas válidas de un universo de 52 municipios adheridos a la Red de Destinos Turísticos Inteligentes de la Comunitat Valenciana (Red DTI-CV, en adelante).

Tabla 3. Características de la muestra.

\begin{tabular}{|c|c|c|c|}
\hline Destino & Emplazamiento & Ámbito de gestión & № de plazas turísticas \\
\hline D1 & Interior & Local & 585 \\
\hline D2 & Interior & Local & 202 \\
\hline D3 & Interior & Local & 200 \\
\hline D4 & Costa & Local & 79.667 \\
\hline D5 & Costa & Local & 921 \\
\hline D6 & Costa & Local & 3.433 \\
\hline D7 & Mixto & Regional & 241.544 \\
\hline D8 & Mixto & Local & 5.224 \\
\hline D9 & Costa & Local & 4.014 \\
\hline D10 & Costa & Legional & 19.788 \\
\hline D11 & Interior & Local & 555 \\
\hline D12 & Interior & Regional & 1.017 \\
\hline D13 & Mixto & Local & 8.311 \\
\hline D14 & Costa & Local & 3.486 \\
\hline D15 & Interior & Regional & 315 \\
\hline D16 & Mixto & Local & 251 \\
\hline D17 & Interior & Local & 670 \\
\hline D18 & Interior & Local & 226 \\
\hline D19 & Interior & & 24 \\
\hline
\end{tabular}




\begin{tabular}{|c|c|c|c|}
\hline D20 & Costa & Local & 8.608 \\
\hline D21 & Costa & Local & 37.413 \\
\hline D22 & Costa & Local & 3.024 \\
\hline D23 & Interior & Local & 179 \\
\hline D24 & Costa & Local & 4.063 \\
\hline D25 & Costa & Local & 17.574 \\
\hline
\end{tabular}

Elaboración propia.

Dicho cuestionario tenía como objetivo analizar la percepción del técnico de cada destino en relación a la importancia de los datos al momento de gestionar su destino.

Sin embargo, para la presente investigación solamente se han analizado las preguntas y respuestas que hacen referencia a los siguientes objetivos específicos (Tabla 4):

-Objetivo específico 1. Identificar las dificultades que impiden la implementación del SGID, y las oportunidades que se derivan de su uso para la gestión del destino.

-Objetivo específico 2a. Analizar la importancia y el tratamiento de los datos durante el proceso de gestión del destino.

-Objetivo específico 2b. Determinar el grado de desarrollo y formación en tecnologías de la información y comunicación de las organizaciones de gestión del destino.

Estos dos últimos objetivos ( $2 \mathrm{a}$ y $2 \mathrm{~b}$ ) han sido planteados al tratarse de dos aspectos clave para comprender la percepción que pudieran tener los gestores al ser preguntados por los SGID.

Para la explotación estadística de los datos recogidos se ha utilizado el programa SPSS Statistics 25.

Tabla 4. Modelo del cuestionario.

\begin{tabular}{|c|c|c|}
\hline $\begin{array}{c}\text { Objetivo } \\
\text { específico }\end{array}$ & Pregunta & $\begin{array}{l}\text { Métrica de } \\
\text { respuesta }\end{array}$ \\
\hline \multirow{2}{*}{$\begin{array}{c}\text { Objetivo } \\
\text { específico } 1\end{array}$} & $\begin{array}{l}\text {-Explique cuáles son las carencias en términos de } \\
\text { información de un destino que podría cubrir un SGID }\end{array}$ & Respuesta abierta \\
\hline & $\begin{array}{l}\text {-Explique cuáles son las oportunidades que podrían } \\
\text { derivarse para un destino turístico del uso de un SGID }\end{array}$ & Respuesta abierta \\
\hline
\end{tabular}




\begin{tabular}{|c|c|c|}
\hline & $\begin{array}{l}\text {-Explique cuáles son las dificultades que podría } \\
\text { presentar para un destino turístico el uso de un SGID }\end{array}$ & Respuesta abierta \\
\hline & $\begin{array}{c}\text { - ¿De qué tipo de herramientas TIC dispone su } \\
\text { organización para la explotación de estadísticas y el } \\
\text { análisis de fuente de información? }\end{array}$ & Respuesta múltiple \\
\hline \multirow{6}{*}{$\begin{array}{c}\text { Objetivo } \\
\text { específico 2a }\end{array}$} & $\begin{array}{l}\text {-Evalúe de forma general la importancia de los datos } \\
\text { en su organización turística }\end{array}$ & Escala del 1 al10 \\
\hline & $\begin{array}{c}\text { - ¿En qué ámbitos de la gestión de su destino turístico } \\
\text { tiene utilidad el análisis de datos? }\end{array}$ & Respuesta múltiple \\
\hline & $\begin{array}{c}\text { ¿Qué tipología de datos ha utilizado su organización } \\
\text { hasta el momento? }\end{array}$ & Respuesta múltiple \\
\hline & $\begin{array}{l}\text {-Valore la importancia para la actividad de su } \\
\text { organización según la fuente de datos: }\end{array}$ & Escala Likert \\
\hline & $\begin{array}{l}\text { - ¿Qué tipología de datos que aún no utiliza pretende } \\
\text { su organización comenzar a analizar en el corto } \\
\text { plazo? }\end{array}$ & Respuesta múltiple \\
\hline & $\begin{array}{l}\text {-¿Qué tipología de datos considera que tendrá más } \\
\text { relevancia en un futuro? }\end{array}$ & Respuesta múltiple \\
\hline \multirow{5}{*}{$\begin{array}{c}\text { Objetivo } \\
\text { específico } 2 b\end{array}$} & $\begin{array}{l}\text {-Durante 2019, ¿alguno de sus empleados ha recibido } \\
\text { formación específica en Big Data? }\end{array}$ & Sí/No \\
\hline & $\begin{array}{l}\text { - ¿Cuenta su organización con personal especialista } \\
\text { en TIC? }\end{array}$ & Sí/No \\
\hline & $\begin{array}{l}\text {-¿Existe un departamento de TIC en su organización? } \\
\qquad \text { ¿Qué funciones desarrolla? }\end{array}$ & Respuesta múltiple \\
\hline & $\begin{array}{l}\text { - ¿Se ha externalizado desde turismo algún servicio } \\
\text { relacionado con las TIC? }\end{array}$ & Respuesta múltiple \\
\hline & $\begin{array}{c}\text { - Sobre la compra de datos. ¿Tiene su organización la } \\
\text { intención de comprar datos para su análisis? }\end{array}$ & Respuesta múltiple \\
\hline
\end{tabular}

Elaboración propia. 


\section{RESULTADOS DE LA INVESTIGACIÓN.}

Con la finalidad de contrastar el grado de aplicabilidad y desarrollo de los sistemas de gestión integral de destino, se ha considerado la Comunidad Valenciana, y de forma específica los destinos pertenecientes a la Red DTI-CV, como un ámbito de estudio idóneo para la aplicación de un análisis específico.

De igual modo, se ha planteado conocer la importancia de los datos para acometer las estrategias de gestión de un destino, así como el grado de desarrollo y formación de las TIC en las OGD, siendo dos aspectos clave para entender la percepción que pudieran tener los gestores en referencia a la oportunidades y dificultades derivadas de la implementación del SGID.

La explotación de los resultados se estructura en tres partes: a) tratamiento y análisis de los datos en el proceso de gestión del destino; b) relevancia y retos del SGID para la gestión del destino; y c) grado de desarrollo y formación TIC en las OGD.

\subsection{Tratamiento y análisis de los datos durante el proceso de gestión del destino.}

Un sistema de gestión integrado de destino tiene como principal objetivo facilitar la recogida, el tratamiento y en análisis de un conjunto de datos para la consecución de las estrategias de la OGD. La importancia y la procedencia que tiene cada uno de estos datos a la hora de gestionar el destino es un indicador clave para orientar el diseño del SGID hacia unas u otras funcionalidades.

Así, los gestores de los destinos han sido preguntados por la importancia de los datos para su OGD (Tabla 5). En este sentido, se observa que, de forma general, los gestores valoran positivamente el uso de los datos para acometer sus estrategias de gestión. No obstante, conviene destacar la existencia de un conjunto de municipios, que bien por desarrollo y tradición turística, emplazamiento, ámbito gestión, u otras casuísticas, sus gestores tienen una valoración más modesta, al respecto. Sería interesante, de cara a una futura línea de investigación, plantear qué variables (tipo de producto turístico, afluencia turística, idiosincrasia socio-territorial, características de las fuentes 
de datos, etc.) condicionan una mayor o menor valoración de la importancia de disponer de datos a la hora de gestionar el destino.

Tabla 5. Valoración de la importancia de los datos en la gestión de los destinos turísticos.

\begin{tabular}{|lccccc|}
\hline & Media & Mediana & Moda & $\begin{array}{c}\text { Desviación } \\
\text { Típica }\end{array}$ \\
\hline Total OGD & & & & & \\
\hline & & & & & \\
Por emplazamiento & Interior & 7,4 & 8 & 10 & 2 \\
& Costa & 8,5 & 9 & 10 & 1,6 \\
& Mixto & 8,2 & 8,5 & - & 1,4 \\
\hline \multirow{2}{*}{ Por ámbito de gestión } & & & & & \\
& Local & 8 & 8 & 10 & 2,1 \\
& Regional & 8,5 & 9 & 10 & 1,6 \\
\hline
\end{tabular}

Elaboración propia.

Los resultados (Figura 5) muestran una clara apuesta de los gestores por los datos procedentes de fuentes tradicionales. Las encuestas turísticas (en las oficinas turísticas, en los atractivos, etc.) junto a la explotación de los registros administrativos son valorados por encima de otras fuentes de información a las que teóricamente se les está asignando más relevancia estratégica y potencialidad como son las plataformas online, las pasarelas de pago, los medios sociales, o los datos extraídos de las sensorización del destino.

Seguramente, la importancia atribuida a cada fuente de información mantenga relación con la posibilidad o no de disponer de éstas. Muchos de los gestores encuestados, no disponen de la tecnología (sistemas de trazabilidad, sistemas de información geográfica, etc.) necesaria para recopilar y analizar datos procedentes, por ejemplo, de las pasarelas de pago o de la sensorización de los movimientos de la demanda. De este modo, el desconocimiento, por no poder disponer de éstas, repercute negativamente en su importancia. Por contra, las fuentes de información más arraigadas a la idiosincrasia del gestor, como por ejemplo, la encuesta en las oficinas turísticas o los datos procedentes de las asociaciones del sector, resultan ser las más valoradas. 
Figura 5. Valoración de la importancia de los datos en la gestión de los destinos turísticos, según la fuente

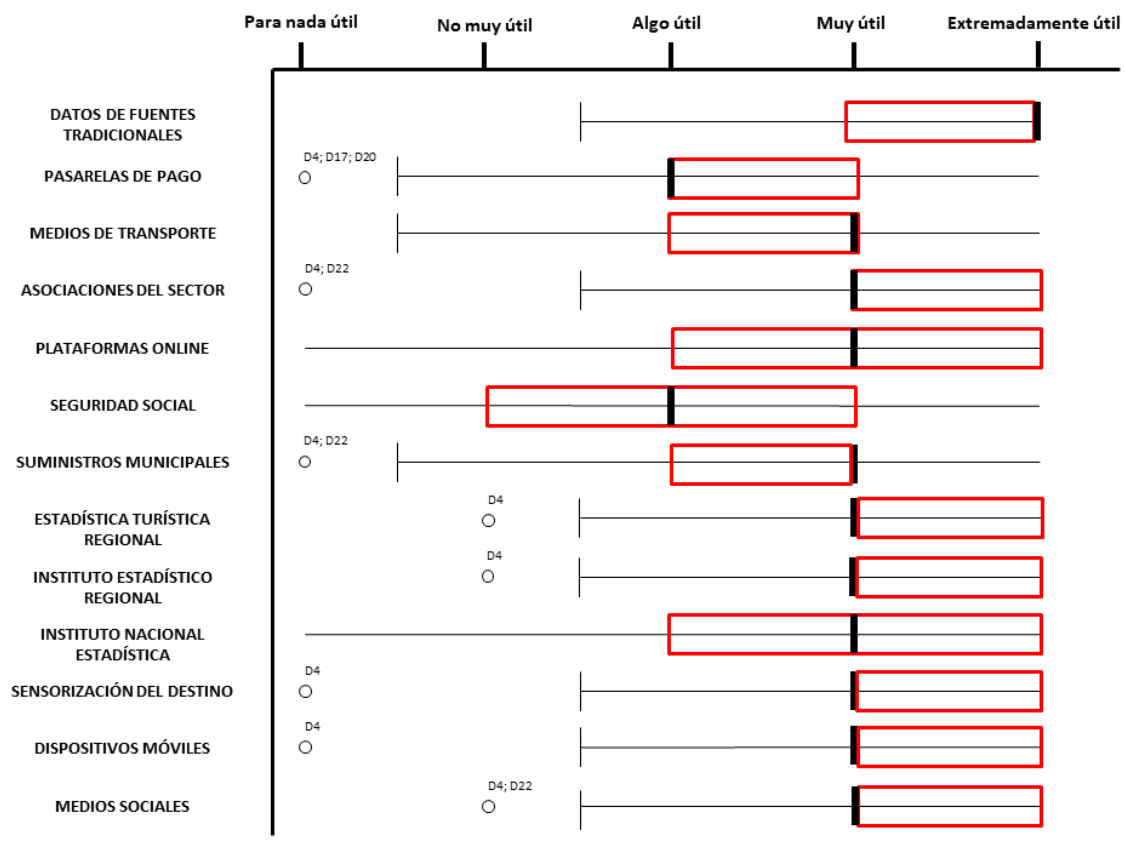

Elaboración propia.

Sin embargo, y de acuerdo con la Tabla 6, las fuentes de información que han sido valoradas como menos importantes resultan ser las más relevantes para el futuro. En consecuencia, se confirma que en la medida en que el gestor pueda disponer de la tecnología necesaria para explotar datos procedentes de dispositivos y plataformas inteligentes, éstos empezarán a utilizarse para confeccionar las estrategias de gestión de su destino.

Tabla 6. Valoración de la relevancia de los datos en la gestión de los destinos turísticos, según la fuente.

\begin{tabular}{|cc|}
\hline Consideran más relevantes para el futuro: & $\begin{array}{c}\text { Porcentaje de los } \\
\text { gestores }\end{array}$ \\
\hline Datos de fuentes tradicionales (encuestas, registros administrativos, etc.) & $44 \%$ \\
\hline Datos de fuentes estadísticas oficiales i de asociaciones del sector: & $24 \%^{*}$ \\
Asociaciones del sector & $36 \%$ \\
Seguridad Social & $36 \%$ \\
Estadística turística regional & $20 \%$ \\
Instituto Regional de Estadística & $12 \%$ \\
\hline Pasarelas de pago & $70 \%{ }^{*}$ \\
Sensores o dispositivos inteligentes en el destino & $44 \%$ \\
Dispositivos móviles & $80 \%$ \\
\hline
\end{tabular}




\begin{tabular}{|c|c|c|}
\hline \multicolumn{2}{|c|}{ Datos procedentes otros sectores y subsectores turísticos } & $22 \%{ }^{*}$ \\
\hline & Medios de transporte & $20 \%$ \\
\hline & Suministros municipales & $24 \%$ \\
\hline Datos generadc & tir de los medios sociales y plataformas online & $48 \% *$ \\
\hline & Medios sociales & $52 \%$ \\
\hline *Media porcentual & Plataformas online & $44 \%$ \\
\hline
\end{tabular}

Elaboración propia.

Otra cuestión a destacar es la moderada valoración, tanto para la utilidad como para la relevancia futura, que han recibido los datos procedentes de otras áreas o sectores no turísticos (de medios de transporte, de suministros municipales), pero de indiscutible relación con la actividad turística.

Igualmente ocurre con los datos procedentes de la Seguridad Social y del Instituto Nacional de Estadística (INE, en adelante). Tanto las fuentes de datos proporcionadas por la Tesorería General de la Seguridad Social como por el INE, presentan una serie de características (periodicidad de publicación de datos, niveles de agregación territorial, continuidad geográfica, selección muestral, etc.) que muchas veces no permite plasmar la idiosincrasia territorial y turística del lugar, y por consiguiente no resulta útil para la gestión del destino. Por ejemplo, muchos municipios del interior de la Comunidad Valenciana, con un incipiente desarrollo turístico, no pueden orientar sus estrategias de gestión en base a los datos de FRONTUR, EGATUR, o la EPA, porque los niveles de agregación territorial no permiten la obtención de los datos en base a su territorio. Por este motivo, los gestores de estos destinos valoran más positivamente las fuentes de datos regionales en detrimento de las fuentes de estadística nacional.

No obstante, en algunos casos, las fuentes de datos procedentes de los institutos de estadística regionales, también presentan las mismas características del INE o de la Seguridad Social. En estos casos, al técnico del destino, no le queda más opción que fundamentar su estrategia turística en base a los datos procedentes de fuentes municipales, o incluso de registros exclusivos del área o del departamento de turismo, perdiendo perspectiva del fenómeno turístico y dificultando su tarea de gestionar. 
Al margen de los aspectos relativos a la importancia de los datos, resulta interesante señalar en qué estrategias los gestores del destino creen que tiene utilidad el análisis de datos.

La Tabla 7 indica que los gestores encuestados creen más útil el análisis de datos para desarrollar estrategias de mercado (marketing, comunicación, estudios de demanda, etc.) que para acometer estrategias de planificación, ordenación y desarrollo del producto.

La razón por la cual los técnicos de gestión creen que los datos tienen más utilidad para abordar estrategias de mercado, podría estar relacionada con la tradicional orientación hacia el marketing y la promoción que han adoptado las OGD. Varios autores señalan que las OGD se han estado especializando como entidades responsables de la gestión efectiva del mercado, por esa razón no resulta extraño que gestores encuestados se decanten por el uso de los datos para abordar este tipo de estrategias.

Sin embargo, dentro de las denominadas estrategias de mercado, resulta significativa la poca valoración que reciben las actuaciones en relación a la comercialización del destino. Claro está que son pocos los destinos que disponen de un sistema de comercialización (Díaz, Guevara y Antón, 2006; Díaz y López, 2012) razón por la cual, han sido pocos los gestores que utilizan estos datos para aborda una toma de decisión estratégica.

Tabla 7. Valoración de la utilidad de los datos en la gestión de los destinos turísticos.

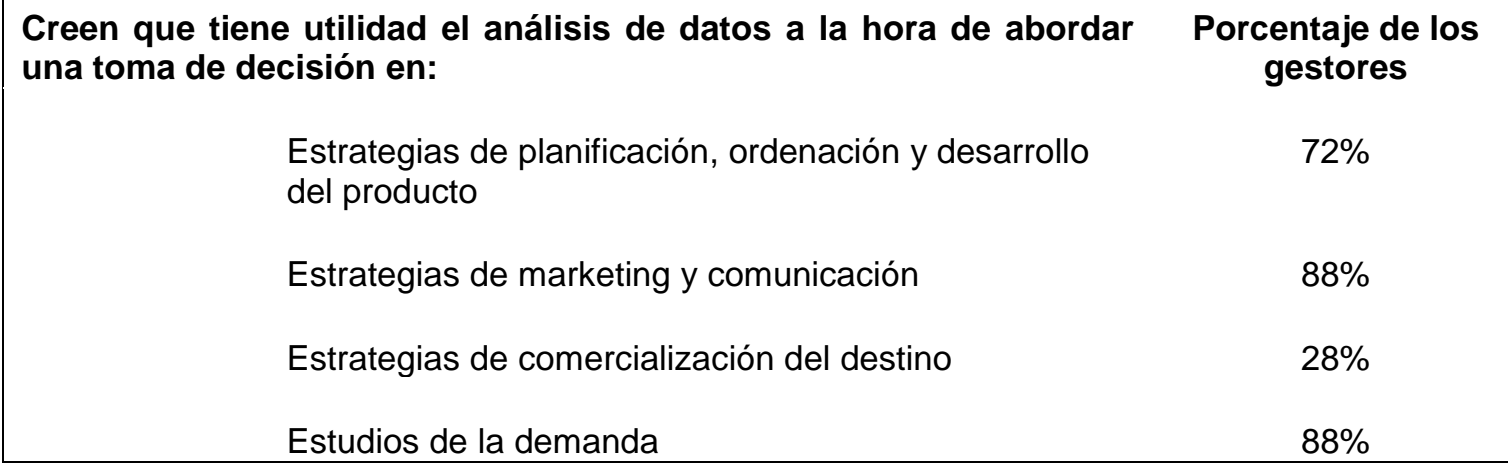

Elaboración propia. 
En cualquier caso, los gestores, cada vez más, recurren a la utilidad de los datos para gestionar otros aspectos como son por ejemplo los relacionados con la planificación, la ordenación y el desarrollo del producto. En este sentido, prácticamente 2 de cada 3 gestores utiliza algún tipo de herramienta de análisis de datos para abordar una toma de decisión al respecto.

\subsection{Relevancia y retos del SGID para gestión del destino.}

Las tecnologías de la información y comunicación han modificado la forma de gestionar el destino. Ahora, los técnicos disponen de nuevas tecnologías que han permitido desarrollar nuevas dinámicas a la hora de abordar los retos estratégicos del destino.

No obstante, la introducción de estas herramientas en los procesos de gestión de los destinos, al menos en relación a un SGID, parece estar desarrollándose de forma muy paulatina.

En este sentido, ningún gestor encuestado cuenta con un SGID. Sin embargo, y aunque la mayoría (el 32\%), solamente, dispone de herramientas de estadística básica, se intuye que los encuestados se muestran muy interesados en iniciar el uso de otras herramientas TIC.

Por este motivo, los gestores han sido preguntados por las dificultades que impiden la implementación de un SGID, y por las oportunidades de su uso que se derivarían de su implementación (Tabla 8).

Tabla 8. Cuadro-resumen de las principales oportunidades y dificultades de un SGID.

\begin{tabular}{|l|lll|}
\hline \multicolumn{1}{|c|}{ Oportunidades de su desarrollo } & \multicolumn{3}{|c|}{ Dificultades para su desarrollo } \\
\hline $\begin{array}{l}\text { Permite obtener datos reales datos reales y } \\
\text { continuos de todos los agentes implicados en } \\
\text { el destino. }\end{array}$ & $\begin{array}{l}\text { Falta de recursos económicos para su } \\
\text { adquisición y mantenimiento. }\end{array}$ \\
\hline $\begin{array}{l}\text { Incrementa la gestión eficiente del destino, } \\
\text { para así hacer más eficiente y eficaz el } \\
\text { proceso de toma de una decisión estratégica. }\end{array}$ & $\begin{array}{l}\text { Las OGD cuentan con personal poco } \\
\text { cualificado para analizar e interpretar los } \\
\text { datos. }\end{array}$ \\
\hline $\begin{array}{l}\text { Se constituye como un canal de información y } \\
\text { comercialización para el turista 100\% } \\
\text { personalizado. }\end{array}$ & Poca colaboración del empresariado. & \\
\hline $\begin{array}{l}\text { Posibilita el hecho de desarrollar } \\
\text { herramientas y tecnología para obtener } \\
\text { información estratégica a partir de la } \\
\text { sensorización de la oferta y demanda. }\end{array}$ & Falta de infraestructura, tecnología & y \\
\hline $\begin{array}{l}\text { Puede contribuir a la reducción del desigual } \\
\text { acceso, en el uso, o en el impacto de las TIC } \\
\text { entre el sector privado. }\end{array}$ & & & \\
\end{tabular}


Es una herramienta estratégica para el desarrollo de la competitividad y sostenibilidad del destino.

Elaboración propia.

En base a los beneficios derivados del desarrollo de un SGID, la mayoría de los gestores coinciden en señalar que este tipo de herramienta incrementa la gestión eficiente del destino. Concretamente, la aplicación de un SGID les reporta una mejora global de la gestión y de la anticipación en la toma de decisiones estratégicas:

"Reporta oportunidades de creación y mejora de productos turísticos, conocer mejor la oferta y la demanda, así como anticiparse a la toma de decisiones y actividades de promoción en cuanto a mercados y clientes potenciales (D4)".

"Mejora el proceso de toma de decisiones tanto al nivel público como al empresariado (...) y adecuarlo a las necesidades de cada uno de los destinos para que se constituya como principal fuente generadora de inteligencia y conocimiento a nivel local (D8)".

"(Mejora) la toma de decisiones (en planificación, gestión, promoción, etc.) de una manera más eficaz, en base a datos reales y predictivos, adaptada a las necesidades de sector y de la demanda (D10)".

Igualmente, conocer mejor las características y las particularidades de la demanda y de la oferta turística, es otro de los beneficios que incurre el desarrollo de esta herramienta:

"(Permite) conocer en mayor concreción el comportamiento del turista: target, movilidad, recursos; toma de decisión de compra (...); nivel de satisfacción en todos los momentos de la cadena de valor turística... (D24)".

"(Permite) medir y analizar los datos turísticos para la mejora de la oferta turística y la toma de decisiones (D19)".

"(Mejora) el desarrollo de productos específicos; promociones directas y específicas; promoción en mercados específicos (D25)".

En este sentido, los gestores destacan la importancia del SGID como canal de información para el turista con la intención de ofrecer un servicio y una experiencia turística eficiente y personalizada: 
"Podría ser un canal de información para el turista para que pudiera acceder en cualquier momento, simplificando la tarea de informar al visitante (D3)".

“(Permite) ofrecer información al visitante en períodos de tiempo en que las oficinas permanecen cerradas al pública, gestión de colas en la visita a los museos, sistemas de aparcamiento inteligente, etc. (D15)".

"Servicio de información al cliente 24/24 horas (D13)".

Otro de los beneficios, imprescindible, para acometer una gestión eficaz y eficiente del destino, es la posibilidad de obtener datos reales y continuos de todos los agentes implicados en el destino:

"Posibilita trabajar en base a datos reales, destacando necesidades y eliminando suposiciones, lo que ayuda a tomar decisiones más acertadas y permite medir el desempeño de las mismas. Deriva en un uso de los recursos más eficiente y en una mejor coordinación del sector (D23)".

"Proporciona datos más concretos y permite filtrar por diferentes criterios (D18)".

"(Permite) obtener información más real o aproximada de lo que está pasando en el destino (D1)".

Y además, un SGID proporciona la oportunidad de disponer de tecnologías concretas para la explotación de los datos obtenidos, para así obtener información estratégica:

"Monitorización de todos los recursos/productos turísticos para medir su evolución (...) Herramientas de análisis multidimensional desde distintas perspectivas. Cuadro de mandos integrado y dashboard. (...) Mejora de la analítica web y de las redes sociales, etc. (D8)".

"Herramientas de valorización de indicadores turísticos (D22)".

"Implementación de tecnologías enfocadas a la mejora de la experiencia turística del visitante (D15)".

Más allá de las oportunidades de acuerdo con la mejora del proceso de producción, promoción y comercialización del destino, los técnicos advierten que el SGID puede dar respuesta a la brecha digital que sufren algunas PYMES del sector: 
"(En el destino) existen dificultades en relación a la brecha digital y en la falta de formación de las PYMES (D24)".

Por este motivo, entienden que un sistema de gestión integrado de destino puede contribuir a la reducción del desigual acceso, en el uso, o en el impacto de las TIC el sector privado:

"Posibilidad de difundir conocimiento a las empresas del sector. Participación de los agentes privados en la generación de información. (...) Generar un barómetro empresarial que tome el pulso al sector, niveles de ocupación, rentabilidad y empleabilidad del sector (D8)."

Los gestores finalmente, han destacado que los SGID resultan ser una herramienta estratégica para el incremento de la competitividad:

“(Aporta) capacidad de diferenciarse apoyándose en el análisis de la información para generar conocimiento y crear ventajas competitivas y nuevas oportunidades (D8)"

"Más competitividad (D6)".

Pero también para el desarrollo sostenible del destino y la mitigación de los impactos derivados de la actividad turística:

“(...) Podríamos mejorar la planificación y la medidas preventivas para no cargarnos la capacidad de carga del destino o del recurso turístico (D16)".

“(...) Mejorar la vida de los ciudadanos en cierto niveles (D25)”.

"Permitir una gobernanza más integral y colaborativa (D8)".

No obstante, a pesar de ser una herramienta estratégica y operativa clave en el incremento de la competitividad y la sostenibilidad del destino, los gestores encuestados advierten que los sistemas de gestión del destino entrañan dificultades y retos para su desarrollo. Una de las cuestiones que más preocupa es la falta de recursos económicos para su adquisición y mantenimiento:

"El principal inconveniente es nuestro caso es el coste que tendría adquirirlo (D4)."

"El presupuesto necesario y su posterior mantenimiento (D13)." 
Otro de los retos que se plantean los gestores para poder desarrollar la herramienta es la necesidad de contar con personal cualificado para analizar e interpretar los datos:

"Otra de las dificultades es la falta de formación del personal existente y la captación de talento en análisis de datos o inteligencia de negocios, perfiles hasta hace poco no requeridos en las instituciones o empresas turísticas (D4)".

"Para un destino pequeño la falta de recursos humanos con formación específica (D17)."

Por otra parte, los gestores no pierden de vista a la importancia de la colaboración pública-privada para la toma de decisiones. La falta de colaboración del empresariado dificulta, muchas veces, la obtención de información integral del destino:

"Hay poca colaboración del empresariado cuando se solicita datos de oferta (D23)".

"Hay falta de colaboración de los empresarios en facilitar los datos (D24)".

Por último, y no menos importante, los gestores apuntan a la falta de infraestructura, tecnología y arquitectura software (interoperabilidad) como principal dificultad para que un destino disponga de un sistema de gestión integrado:

"El destino no (...) dispone de fuentes estructuradas o de herramientas de gestión de la información adecuadas (...) ni tampoco de espacios u oficinas para el análisis y el desarrollo (D4)".

"Las principales dificultades las encontramos en el momento de su implementación (D18)".

"Muchos destinos no tienen claro como configurar el sistema porque no han normalizado el proceso de vigilancia e inteligencia de los datos (D4)".

\subsection{Grado de desarrollo y formación TIC de las organizaciones de gestión turística.}

Con la intención de analizar el grado de desarrollo y formación de las TIC en las organizaciones de gestión del destino se han planteado varias cuestiones al respecto. 
En un primer término se les ha preguntado por la existencia de un departamento en la OGD dedicado a las TIC, y, en caso de su existencia, las funciones que se desarrollan con respeto a la gestión turística.

De los datos se desprende un porcentaje bajo (alrededor del 35\%) de OGD que cuentan con un departamento dedicado a las TIC. En su mayoría son departamentos compartidos con otras áreas (de promoción económica, social, medioambiental, etc.). Por lo tanto, soy muy pocas las organizaciones de gestión turística que cuenten con un departamento TIC exclusivo para la actividad turística.

Por esa razón, los gestores manifiestan que la mayoría de servicios turísticos relacionados con las TIC (mantenimiento web, software, análisis de datos y gestión de las redes sociales, etc.), son externalizados.

No obstante, son pocas las OGD que tienen la intención (en torno al 26\%) o que han comprado (aproximadamente un 14\%) datos para su análisis. En su mayoría han sido compras de datos masivos, proporcionados por plataformas especializadas.

A pesar de ello, la tendencia actual en las OGD, apunta hacia el crecimiento de la contratación de datos a través de proveedores externos para la digitalización de la estrategia de gestión del destino, fundamentalmente debido a que las OGD locales no disponen del know-how, de la tecnología ni recursos necesarios para gestionar datos tan precisos como los que pueden llegar a ofrecer las empresas especializadas. Es importante que se preste mucha atención en el tipo de empresa que se contrata ya que pueden derivarse situaciones especialmente comprometidas para la OGD.

Es importante tomar en consideración la solvencia económica y/o técnica de las empresas que ofrecen los servicios. En este sentido, una contratación dónde no se consideran éstos parámetros puede suponer un riesgo para la estrategia de la gestión de datos ya sea por falta de medios adecuados $u$ obsolescencia del SGID.

Sería recomendable, también, que las OGD regionales o nacionales, representasen los entes competentes de la gestión local con el fin de que su 
poder de negociación sea mucho mayor frente a las empresas contratistas, y así establecer un marco de contratación común para todas las OGD locales de su ámbito. Además, habría la posibilidad de desarrollar un sistema de calidad y control de los datos suministrados a las OGD locales, para garantizar su validez y fiabilidad.

Otra cuestión por la que los gestores han sido preguntados, ha sido en relación a su formación en TIC. En este sentido, menos de la mitad de las OGD cuentan con personal especialista en TIC. Sin embargo, varios gestores encuestados (más del $40 \%$ ) señalan que durante el 2019, han recibido formación específica en análisis de datos masivos.

A la vista de lo expuesto no es de extrañar que los gestores señalen, que la falta de personal cualificado en materia TIC sea uno de los principales impedimentos en la implementación de un SGID. 


\section{CONCLUSIONES Y RECOMENDACIONES.}

El ciudadano actual se encuentra inmerso en la sociedad de los datos. Cada día se producen y se consumen grandes cantidades de información. La cultura de los datos es imparable.

Si bien es cierto que en otros muchos sectores económicos el tráfico de datos es continúo y abundante, la digitalización de la actividad turística ha provocado que el sector se constituya como uno de las principales actividades sociales en la generación de volúmenes de información. Datos que deben ser procesados y analizados para su correcta integración en las estructuras y estrategias de gestión de las empresas y destinos turísticos.

En la práctica, la gestión de los datos turísticos es una asignatura pendiente de la mayoría de las OGD.

La visión cortoplacista de la política turística, junto con la posibilidad de que los datos demuestren una realidad no compartida con los intereses del planeamiento turístico, pudiendo generar un conflicto, hacen que elaborar una estrategia de gestión de datos no sea un prioridad para los gestores del destino. Además, ésta gestión no tiene una repercusión económica directa; por lo tanto, son pocos los destinos que cuenten con estrategia bien desarrollada.

No obstante, los resultados del presente trabajo demuestran que los gestores turísticos de los destinos adheridos a la RED DTI-CV se preocupan, cada vez más, por la necesidad de disponer de datos reales y predictivos sobre su destino. Las fuentes de datos tradicionales (encuesta en la oficina de turismo, registros administrativos, etc.) siguen siendo las más utilizadas para la obtención de éstos. Sin embargo, a medida que se van implementando, de manera paulatina, nuevos métodos tecnológicos, los técnicos empiezan a valorar otras fuentes del entorno online.

En este contexto, la implementación de un sistema de gestión integrado de destino, permite dar interoperabilidad entre estos nuevos métodos, con la finalidad de mejorar la eficiencia y la eficacia del proceso de gobernanza turística. 
No obstante, el desarrollo del sistema tiene numerosos impedimentos que imposibilitan, por el momento, su plena funcionalidad: costes económicos inasumibles por parte de las entidades de gestión turística, falta de gestores turísticos formados en tecnologías de la información y comunicación, poca colaboración público-privada por motivos de desconfianza, brecha digital, etc.

Tabla 9. Cuadro-resumen de las principales líneas de acción para fomentar la implementación de un SGID.

\begin{tabular}{|l|l|}
\hline \multicolumn{1}{|c|}{ Objetivo } & \multicolumn{1}{|c|}{ Acción concreta } \\
\hline $\begin{array}{l}\text { Mejorar el proceso de recogida de } \\
\text { información, procesado, visualización e e } \\
\text { interpretación de los datos turísticos. }\end{array}$ & $\begin{array}{l}\text { 1. Diseñar una estrategia de gestión integral } \\
\text { de los datos mediante la implementación de } \\
\text { un SGID. }\end{array}$ \\
\hline $\begin{array}{l}\text { Implementación y mantenimiento de un SGID } \\
\text { en un destino. }\end{array}$ & $\begin{array}{l}\text { 2. Promover líneas de ayuda por parte de la } \\
\text { administración pública. }\end{array}$ \\
\hline $\begin{array}{l}\text { Disponer de personal cualificado en TIC en } \\
\text { las OGD. }\end{array}$ & \begin{tabular}{l} 
3. Fomentar programas y cursos de formación \\
\hline Datos turísticos del destino en abierto
\end{tabular} \\
\hline
\end{tabular}

Elaboración propia.

Por este motivo, de acuerdo también con las líneas teórico-conceptuales plateadas, se sintetizan cuatro recomendaciones generales y sus principales líneas de acción, para así fomentar el desarrollo de un SGID en un destino (Tabla 9):

- 1. Diseñar una estrategia de gestión integral de los datos turísticos. Es importante planificar un proceso de generación, almacenamiento y reutilización de los datos, cuyo propósito se adecue a la estrategia de gestión del destino y a los principios de buena gobernanza.

- 2. Promover líneas de ayuda para la implantación y el mantenimiento de un SGID. Uno de los principales impedimentos a la hora de desarrollar un sistema de gestión, es la falta de recursos económicos. Los costes del desarrollo, implementación y mantenimiento resultan inabarcables para los presupuestos de las OGD. Por este motivo, se insta a las administraciones públicas supramunicipales la creación de líneas de ayuda para el desarrollo de este tipo de iniciativas, alineadas con las estrategias DTI o de ciudad inteligente. 
- 3. Fomentar programas y cursos de formación en TIC, y más concretamente en Data Science, para el personal que gestiona el destino. El tratamiento de datos es un elemento fundamental en la gestión de un destino, uno de sus activos más importantes en torno al cual se articulan las estrategias. Resulta apremiante contar con recursos humanos especializados en TIC, para que la organización competente en la gestión del destino pueda ofrecer un modelo estratégico y operacional adaptado al nuevo ecosistema online.

- 4. Promocionar la abertura de datos en turismo. De acuerdo con Celdrán-Bernabeu, Mazón y Giner (2018) el uso de datos en abierto puede favorecer el desarrollo de destinos innovadores, donde sector público y privado compiten y colaboraran para hacer del lugar un destino más competitivo y sostenible, ofreciendo una mejor experiencia al turista. Es muy importante que, en la medida de lo posible, la arquitectura software del SGID responda a un sistema "open data", para así favorecer un ecosistema innovador en el destino, para, por ejemplo, reutilizar los datos generados en el SGID para el desarrollo de otras soluciones inteligentes.

Entre las líneas de investigación futuras se hace especialmente interesante realizar un estudio exploratorio y comparado, a nivel internacional, sobre buenas prácticas en relación al desarrollo de los SGID con el fin de identificar una metodología de gestión de datos turísticos, y más concretamente, sobre el desarrollo de los sistemas de gestión.

Asimismo, resulta necesaria la revisión conceptual y práctica del papel de la gestión inteligente en el destino, ya que se ha podido constatar, junto a otros estudios, una perversión del término. Gestionar de forma inteligente, no significa, exclusivamente, digitalizar los procesos de gestión, mediante el desarrollo de herramientas tecnológicas para que puedan aportar más datos sobre el destino. Los datos por si solos carecen de utilidad relevante.

En el proceso de gestión inteligente prevalece el principio de relevancia al del aprovechamiento de todos los datos disponibles. Frecuentemente el gestor del 
destino no toma una decisión adecuada por la iteración o falta de calidad de los datos, por lo que el desarrollo de un sistema de gestión integrado supondrá una mayor tasa de eficiencia y efectividad al momento de implementar las estrategias de gobernanza del destino. 


\section{BIBLOGRAFIA.}

Aguayo, A. (2015). Diseño de un sistema integrado de gestión de destinos turísticos. Tesis doctoral presentada en la Universidad de Málaga.

Benckendorff, P.J., Sheldon, P.J. y Fesenmaier D. R. (2014). Tourism Infomation Technology. CAB International.

Bornhorst, T., Brent-Ritche, J. R. y Sheehan, L. (2010). Determinants of tourism success for DMOs \& destinations: An empirical examination of stakeholders' perspectives. Tourism Management, 31(5), 572-589.

Celdrán-Bernabeu, M.A., Mazón, J. N. y Giner, D. (2018). Open Data y turismo. Implicaciones para la gestión turística en ciudades y destinos turísticos inteligentes. Investigaciones Turísticas, 15, 49-78.

Choi, S., Lehto, X. Y. y Oleary, J. T. (2007). What does the consumer want from a DMO website? A study of US and Canadian tourists' perspectives. International Journal of Tourism Research, 9(2), 59-72.

Cohen, E. (2005). Principales tendencias en el turismo contemporáneo. Política y Sociedad, 42(1), 11-24.

D'Ambra, J. y Mistilis, N. (2010). Assessing the e-capability of visitors information centers. Journal of Travel Research, 7(2), 91-102.

Díaz, C. y Santana A. (2016). Re-motivación en destinos turísticos, redistribución y poder. Revista CIDOB d'Afers Internacionals, 113, 107-122.

Díaz, P. y López, B. (2012). La promoción turística oficial en Internet y su relación con el desarrollo turístico de los destinos: Una aplicación a las Ciudades medias de Andalucía. Revista de estudios regionales, 93, 93-118.

Díaz, P., Guevara, A. y Antón, S. (2006). La presencia en Internet de los municipios turísticos de sol y playa. Mediterráneo y Canarias. En: Actas del VI Congreso de Turismo y Tecnologías de la Información y las Comunicaciones TURITEC. 
EMT. (2017). The European Cities Marketing. Benchmarking report. Modul Vienna University.

Estevão, J. V., Carneiro, M. y Teixeira, L. (2012). The Role of DMS in Reshaping Tourism Destinations: An Analysis of Portuguese Case. Information Technology \& Tourism: Applications, Methodologies, Techniques, 12(3), 161176.

Femenia-Serra, F., Neuhofer, B. y Ivars-Baidal J. A. (2019). Towards a conceptualisation of smart tourists and their role within the smart destination scenario. The Service Industries Journal, 39(2), 109-133.

Gräbner, D., Zanker, M., Fliedl, G. y Fuchs, M. (2012). Classification of Customer Reviews based on Sentiment Analysis. En: 9th Conference on Information and Communication Technologies in Tourism (ENTER).

Giner, D. (2016). Social media marketing en destinos turísticos. Situación actual, planificación y prospectiva. Un análisis aplicado a la Comunidad Valenciana. Tesis doctoral presentada en la Universitat d'Alacant.

Giner, D. (2017). Social media marketing en destinos turísticos. Implicaciones y retos de la evolución del entorno online. Editorial UOC.

Guevara, A., Caro, J. L., Rossi, C., Aguayo, A. y Leiva, J. L. (2010). Sistema integrado de gestión de destinos. En: Turitec 2010. VIII Congreso Turismo y Tecnologías De La Información y Las Comunicaciones.

Ivars-Baidal, J. A., Celdrán-Bernabeu, M. A., Mazón, J. N. y Perles-Ivars, A. F. (2017). Smart destinations and the evolution of ICTs: a new scenario for destination management? Current Issues in Tourism. 22(13) 1581-1600.

Ivars, J. A., Solsona, F. J. y Giner, D. (2016). Gestión turística y tecnologías de la información y la comunicación (TIC): El nuevo enfoque de los destinos inteligentes. Documents d'Anàlisi Geogràfica, 62(2), 327-346.

Ivars-Baidal, J. A. y Vera, J. F. (2019). Planificación turística en España. De los paradigmas tradicionales a los nuevos enfoques: planificación turística inteligente. Boletín de la Asociación de Geógrafos Españoles, 82, 1-31. 
Laesser, C. y Beritelli, P. (2013). St. Gallen Consensus on Destination Management. Journal of Destination Marketing \& Management, 2, 46-49.

Leiva, J. L. (2014). Realidad Aumentada bajo Tecnología Móvil basada en el Contexto Aplicada a Destinos Turísticos. Tesis doctoral presentada en la Universidad de Málaga.

Mastorakis, G., Trihas, N., Perakakis, E. y Kopanakis, I. (2015). E-CRM in tourism exploiting emerging informationand communication technologies. An International Journal of Tourism and Hospitality Research, 26(1), 32-44.

Miralbell, O. (2012). Webs de xarxes socials $i$ intercanvi de coneixement. Ànalis de l'adopció $i$ ús dels membres de les comunitats virtuals professionals del turismo. Tesis doctoral presentada en la Universidad Oberta de Catalunya.

OMT. (2019). Directrices de la OMT para el fortalecimiento de las organizaciones de gestión de destinos (OGD). Preparando las OGD de cara a nuevos retos. Organización Mundial del Turismo.

Ortega, E., Rodríguez, B. y Kitchen, P. J. (2014). The effects of information at tourism destinations: A model proposal. The Marketing Review, 14(2), 111-129.

Pearce, D. (2016). Interdependent destination management functions. Tourism Recreation Research, 41(1), 37-48.

Pike, S. (2008). Destination marketing. An integrated marketing communication approach. Butterworth-Heinemann.

Presenza, A., Sheehan, L. y Ritchie, J. B. (2005). Towards a model of the roles and activities of destination management organizations. Journal of Hospitality, Tourism and Leisure Science, 3(1), 1-16.

Pulido-Fernández, M. C. y Pulido-Fernández, J. I. (2014). ¿Existe gobernanza en la actual gestión de los destinos turísticos? Estudio de casos. Revista de Turismo y Patrimonio Cultural, 12(4), 685-705.

Scarpino, M.R. y Gretzel, U. (2015). Conceptualizing organizational resilience. En: Ritchie, B. y Campiranon, K. (eds) Tourism Crisis and Disaster Management in the Asia-Pacific. CAB International 
Sigala, M. (2011). Developing Destination Management Systems (DMS): roles, functionality and future trends. Inovação em Turismo e Hotelaria, 1, 103-121

Song, H., Liu, J. y Chen, G. (2013). Tourism value chain governace: Review and Prospects. Journal of Travel Research, 52(1), 15 -28.

Vera, F., López, F., Marchena, M. J. y Anton, S. (2011). Análisis territorial del turismo y planificación de destinos turísticos. Tirant lo Blanch.

Wang, Y y Pizam, A. (2011). Destination Marketing and Management. Theories and Applications. CAB International.

Zach, F., Xiang, Z. y Fesenmaier, D. (2007). An assessment of innovation in web marketing: investigating American convention and visitors bureauz. ENTER, 16(1), 365-376. 